\title{
EKC in Hubei Province and its Influencing Factors Analysis
}

\author{
Huiyuan Liu ${ }^{1, a}$, Ailin Zhang ${ }^{2, b}$ \\ 1,2 School of Statistics and Mathematics Administration, Shanghai Finance University, \\ Shanghai,201209,China

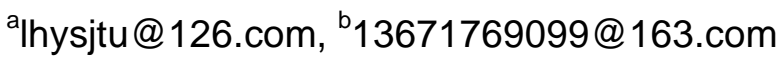

Keywords: Kuznets Curve hypothesis, Carbon emissions, Economic growth, Low carbon development

\begin{abstract}
In this paper we study the relationship between economy growth and carbon dioxide emissions in Hubei Province by building Environmental Kuznets Curve, adding some influencing factors. The result shows that there is Kuznets' inverted U-shaped curve in Hubei Province, and the inflection point did exist in, which proving Kuznets inverse "U" shaped hypothesis. The factors like the development of technology and economy, the upgrade of industry structure and energy structure and FDI will have good effects on carbon dioxide emissions, while the level of urbanization will have side effects on it. So the authorities should find the balance between economy and environment by upgrading structure and the way management, developing green energy resources.
\end{abstract}

\section{Introduction}

The Heads of State, Heads of Government, Ministers, and other heads of delegation present at the United Nations Climate Change Conference 2009 in Copenhagen made Kyoto Protocol more detailed under the principles and provisions of the Convention, and signed Copenhagen Accord finally[1]. The Chinese government promised that per unit of GDP carbon emissions to 2020 on the basis of 2005 fell by $40 \% \sim 45 \%$ in the conference. Beijing, Tianjin, Shanghai, Chongqing, Wuhan, Guangzhou and Shenzhen are chosen as pilot cites to study how to reduce the amount of carbon emission, hoping to complete the promise. As the application of the policy like developing the middle, the local economy grew with the steadily rising carbon emission, it is urgent to develop sustainable economy.

EKC is generally used to study the relationship between economy growth and carbon emission in world. The hypothesis of EKC is firstly mentioned by Gene Grossman and Alan Krueger(1991) in the article Economic Growth and the Environment, later they used statistics regression model to analysis Urban air pollution concentration, water pollution index and GDP per capita, drawing the conclusion that the quality would be better once the economy growth reached to some certain level[2]. Grossman thought EKC was the natural result of economy growth.

EKC is generally used to study the relationship between economy growth and carbon emission in world[3]. The hypothesis of EKC is firstly mentioned by Gene Grossman and Alan Krueger(1991) in the article Economic Growth and the Environment, later they used statistics regression model to analysis Urban air pollution concentration, water pollution index and GDP per capita, drawing the conclusion that the quality would be better once the economy growth reached to some certain level.

Although the study of EKC in China falls behind the developed countries, the study gains its popularity as the environmental problem becoming worse. Xu guoquan(2006) used Divisia to analysis the influencing factors to Chinese carbon emission, thinking that the sharp rise was contributed to the fact that the influence of driving factors overtaking that of inhibited factors[4]. Qi chengxiang(2012) divided Chinese into three parts: east, middle and west, and compared the amount of carbon emission[5]. Shen yongchang(2014) established smooth transition model to study whether the EKC existed in developing regions, using indicators in Anhui Province[6]. Chao fenxiang(2012) got the Inflection point through setting EKC, and confirmed the existence of inverted u-shaped EKC[7]. Establishing EKC in Hubei Province to study the relationship between economy growth and carbon emission, adding some influencing factors based on previous researches to build the final model. Some policies are set to help the economy in Hubei Province grow environment-friendly. 


\section{Empirical research in Hubei Province}

Along with the lucubration on global warming problem, Environmental Kuznets Curve is gradually used to study the relationship between economy growth and carbon emission[8]. The empirical research in Hubei Province is based on the theory of EKC in this article, and some influencing factors are chosen to make further study. According to the final model, policy proposals are given to the authority to make the economy growth environmental-friendly.

\section{The theory of EKC}

The notion of EKC was first mentioned by Grossman and Krueger in 1991, but the theory was finally set by Panayotou in1996, from then on, EKC has been used to study the relationship between economy and environment. The model is usually divided into three types[9]:

Quadratic function

$$
Y=\beta_{0}+\beta_{1} X+\beta_{2} X^{2}+\varepsilon
$$

Cubic function

$$
\boldsymbol{y}=\beta_{0}+\beta_{1} X+\beta_{2} X^{2}+\beta_{3} X^{3}+\varepsilon
$$

Logarithmic function

$$
\ln Y=\beta_{0}+\beta_{1} \ln X+\beta_{2}(\ln X)^{2}+\varepsilon
$$

Y:per capita carbon emission in Hubei Province, X:GDP per capita in Hubei Province, $\varepsilon$ : random error term.

\section{Indicator selection}

GDP per capita is used to be the economic growth, we select data of carbon emission still has not been directly disclosed by Chinese government to describe Carbon emission. According to China Energy Statistical Yearbook,the energy resource used in daily life can be divided into nine parts, including coal, gasoline, diesel, natural gas, kerosene, fuel oil, crude oil, electric power and coke, the equation mentioned in article written by $\mathrm{Xu}$ guoquan-the factor decomposition model and empirical analysis of Chinese carbon emission1995 2004 is used to calculate carbon emission. First the coefficient of coal and coke are assumed to share the same value, and that of gasoline, diesel, kerosene, fuel oil and crude oil are also regarded as same. Then we use the equation (4) to calculate the carbon emission[10,11].

$$
C=\sum_{i} \frac{E_{i}}{E} \times \frac{C_{i}}{E_{i}} \times E=\sum_{i} S_{i} \times F_{i} \times E
$$

$E$ : Total consumption of primary energy in Hubei Province, $F_{i}$ : Carbon intensity of energy, $\mathrm{S}_{i}$ : The percentage of energy.

Table 1 Carbon intensity of energy unit ( $\mathrm{T}$ tons of carbon/ten thousand tons of standard coal )

\begin{tabular}{c|c|c|c}
\hline items & coal & fossil & gas \\
\hline $\begin{array}{l}\mathrm{F}_{\mathrm{i}}(\mathrm{T} \text { tons of carbon/ten } \\
\text { thousand tons of standar } \\
\text { coal })\end{array}$ & 0.7476 & 0.5825 & 0.4435 \\
\hline
\end{tabular}

\section{The Empirical Results and Analysis}

The first step is to draw the scatter plot between per capita carbon emission and GDP per capita, according to the Fig. 1, we can conclude that it is non-linear relationship exists between two variables, which fits hypothesis of inverted u-shaped Environment Kuznets curve, showing that EKC exits in Hubei Province, but more analysis still need to be done to confirm the final model. 


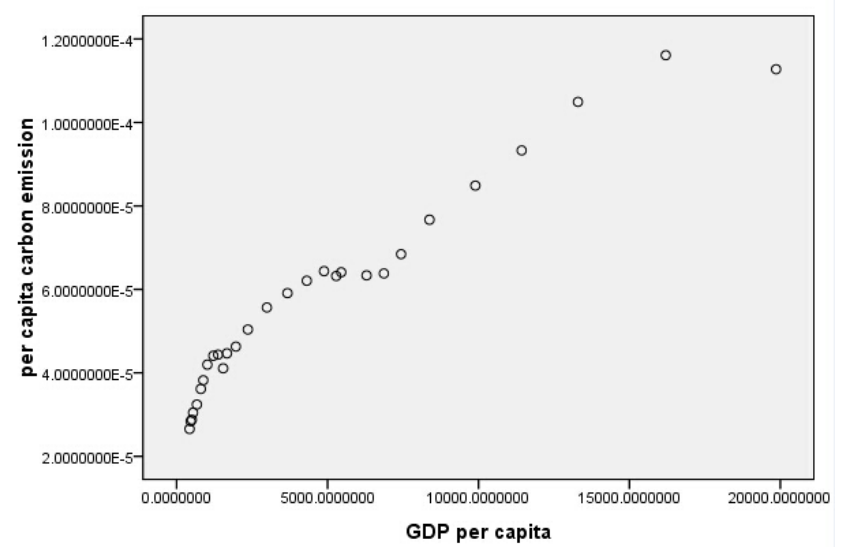

Figure 1 scatter plot

The relationship between GDP per capita and per capita carbon emission is decided by EViews8, the results can be seen in Table 2 .

\begin{tabular}{c|l|l|l|l|c}
\multicolumn{2}{c}{ Table 2 } & \multicolumn{1}{c}{$\mathrm{t}_{2}$} & $\mathrm{t}_{3}$ \\
\hline & \multicolumn{1}{|c|}{$\mathrm{F}$ value } & \multicolumn{1}{c}{$R_{a}{ }^{2}$} & $\mathrm{t}_{1}$ & & \\
\hline Quadratic & 391.6671( & 0.9654 & 13.1527 & -4.3791 & $* * * * * * * *$ \\
function & $\mathrm{p}=0)$ & & $(\mathrm{p}=0)$ & $(\mathrm{p}=0.0002)$ & \\
Cubic & 251.5401( & 0.9640 & 5.32509 & -0.5375 & -0.213150 \\
function & $\mathrm{p}=0)$ & & $(\mathrm{p}=0)$ & $(\mathrm{p}=0.5957)$ & $(\mathrm{p}=0.8329)$ \\
Logarithmic & 507.6375( & 0.9731 & 0.34348 & 1.6823 & $* * * * * * * *$ \\
function & $\mathrm{p}=0)$ & & $(\mathrm{p}=0.734)$ & $(\mathrm{p}=0.1045)$ & \\
\hline
\end{tabular}

It is not hard to find that the F-value(507.6375) and $R_{a}^{2}$ ( 0.9731$)$ of logarithmic function are both maximum in table 2, which shows that the function fits the data most, but quadratic

coefficients (1.6823) is greater than 0 , meaning the curve is downwards-opening, that is opposite to the scatter plot, so it is taken out of account. The goodness of fit of quadratic function and cubic function are almost same, but the coefficient tests are not significant in cubic function $\left(p_{2}=0.5957, p_{3}=0.8329\right)$, indicating $\mathrm{x} 3$ should be removed from the function. The model is chosen as quadratic function:

$$
\hat{Y}=3.057 \times 10^{-5}+6.957 \times 10^{-9} X-1.308 \times 10^{-13} X^{2}
$$

The inflection point is $\left(25693.27,1.2307 \times 10^{-4}\right)$, it shows that the economy growth is no longer at the cost of environment as long as the amount of per capita carbon emission and GDP per capita in Hubei Province reached to the inflection point, meaning that the growth of economy will help to release the environmental problem.

\section{The Influencing Factors in Hubei Province}

The system of environment and economy is very complicated, the influencing factors cannot be said little. Having a try on the development pattern in Hubei Province through choosing some explaining variables, which takes the previous study into account.

\section{The Variables Choosing}

(1) The industry structure: The demand of energy varies with leading part of industry structure, the inverted u-shaped EKC is based on this difference. The progress of industry structure transform usually goes through three parts. The upgrade of structure is reached through some policies, based on developing technology.

(2) The development of technology: The decrease on carbon emission caused by the improvement of technology can be divided into two parts. First those sustainable development energy got by scientific research can take place fossil energy to reduce the carbon emission. Second the upgrade of industry and energy structure also can be reached through the technology developing. 
(3) The energy structure: The impact of energy structure is usually divided into energy consumption structure and energy efficiency. Generally speaking, the energy consumption giving priority to coal energy results in the rising of carbon emission, while the energy efficiency will lead to totally opposite influence. Energy consumption is regarded as the basement of economy growth, so it is no wonder take it as the key cause to environment pollution, but if it is the consumption of green energy rather than fossil energy, there will be no harm to the environment. As for the energy efficiency, it will be risen by the developing technology to control carbon emission.

(4) Global trade: There is no clear relationship between global trade and carbon emission, some people think that the pollution is brought from developed countries to developing countries through global commerce, while others believe that the positive effects brought from foreign invest can overtake its negative effects.

(5) Urbanization: Although the relationship between urbanization and carbon emission has not been defined, indicating that the impact it brings can be regarded as positive or not, the influence did exist.

The empirical results and analysis

The analysis model of influencing factors is assumed, according to the influencing factors, as: $Y=\beta_{0}+\beta_{1} X_{1}+\beta_{2} X_{2}+\beta_{3} X_{3}+\beta_{4} X_{4}+\beta_{5} X_{5}+\beta_{6} X_{6}+\beta_{7} X_{7}+\beta_{8} X_{8}+\beta_{9} X_{9}+\beta_{10} X_{10}+\varepsilon(6)$

The economy growth: GDP per capita $\left(\mathrm{X}_{1}\right), \mathrm{GDP}^{\wedge} 2$ per capita $\left(\mathrm{X}_{2}\right)$.

The industry structure: the percentage of GDP produced by primary industry $\left(\mathrm{X}_{3}\right)$, the percentage of GDP produced by secondary industry $\left(\mathrm{X}_{4}\right)$, the percentage of working population in tertiary industry $\left(\mathrm{X}_{5}\right)$.

The energy structure: energy consumption per unit $\operatorname{GDP}\left(\mathrm{X}_{6}\right)$, the percentage of coal energy consumption $\left(\mathrm{X}_{7}\right)$.

Global trade: $\ln ($ import $)\left(\mathrm{X}_{8}\right), \ln (\mathrm{FDI})\left(\mathrm{X}_{9}\right)$.

Urbanization: the percentage of urban population $\left(\mathrm{X}_{10}\right)$.

The linear regression model is got through SPSS in the way of backward, deleting some variables, the result is shown in Table 3.

\begin{tabular}{c|c}
\multicolumn{2}{c}{ Table 3 } \\
\hline Erase Variables & Final Variables \\
\hline $\mathrm{X}_{1}$ & $\mathrm{X}_{2}$ \\
& $\mathrm{X}_{3}$ \\
$\mathrm{X}_{4}$ & $\mathrm{X}_{5}$ \\
& $\mathrm{X}_{6}$ \\
$\mathrm{X}_{8}$ & $\mathrm{X}_{7}$ \\
& $\mathrm{X}_{9}$ \\
& $\mathrm{X}_{10}$ \\
\hline
\end{tabular}

It can be seen in Table 3 that the eraser variables include $X_{1}, X_{4}$ and $X_{8}$, the remaining explaining variables are retained in the equation, and their coefficients can be seen in Table 4 .

\begin{tabular}{|c|c|c|c|}
\hline & Table 4 & Coefficient & \\
\hline Variables & Coefficient & T-value & P-value \\
\hline $\mathrm{c}$ & $-8.78 \mathrm{E}-05$ & -6.3624 & 0.0000 \\
\hline$X_{2}$ & $-2.14 \mathrm{E}-14$ & -4.3855 & 0.0005 \\
\hline$X_{3}$ & $2.62 \mathrm{E}-05$ & 2.8097 & 0.0132 \\
\hline$X_{5}$ & $-1.71 \mathrm{E}-05$ & -2.0600 & 0.0572 \\
\hline$X_{6}$ & 206.0065 & 36.2035 & 0.0000 \\
\hline$X_{7}$ & 9.99E-07 & 12.5551 & 0.0000 \\
\hline $\mathrm{X}_{9}$ & $-9.27 \mathrm{E}-07$ & -2.0549 & 0.0577 \\
\hline$X_{10}$ & $2.16 \mathrm{E}-05$ & 1.9883 & 0.0653 \\
\hline
\end{tabular}

The final model : 
$\hat{Y}=-8.78 \times 10^{-5}-2.14 \times 10^{-14} X_{2}+2.62 \times 10^{-5} X_{3}-1.71 \times 10^{-5} X_{5}+206 X_{6}+9.99 \times 10^{-7} X_{7}-9.27 \times 10^{-7} X_{9}+2.16 \times 10^{-5} X_{10}$

$\mathrm{F}=4135.571, \mathrm{p}=0<0.05$, meaning that the equation is significant, what's more $R_{a}^{2}=0.9948$, indicating that the equation fits the data well.

(1) The level of economy development represented by per GDP^2 will help to ease the environmental problem, the regression coefficient is $-2.14 \mathrm{E}-14$, and the coefficient tests are significant. So it is not hard to conclude that the carbon emission will decrease with the economic development.

(2) The increase of the proportion held by primary energy gives rise to the carbon emission. Although the primary industry dominates the industrial structure pattern in Hubei Province, the value will decrease through the development of economy and technology.

(3) The another variable indicated the industrial structure is the percentage of working population of the tertiary industry, and the variable will help to ease the problem. The coefficient tests are not significant, and the coefficient is $-1.71 \mathrm{E}-05$. Although the primary industry takes the leading part in Hubei Province, $\mathrm{X}_{5}$ will grow with the development of the tertiary industry, and the structure is gradually transformed to the ideal state which dominated by the tertiary.

(4) The energy consumption per unit GDP is the main way to decrease the carbon emission, the regression coefficient of the variable is 206, meaning that the carbon emission will be reduced by 206 units through one unit raises.

(5) The proportion of coal energy holds is going to worsen the problem of carbon emission, the value will drop with the energy structure optimization, furthermore the green energy is going to replace those primary energy.

(6) The raise of FDI results in the carbon emission decreasing, the so-called environmental refuge theory does not exist in Hubei Province. According to the coefficient tests, the variable is not significant. Hubei Province located in the middle part of China, so its attraction to foreign investment is far less than those coastal cities, but the percentage it represents will grow with the economy growth.

(7) The urbanization level indicated by the urban population proportion will promote the carbon emission, the coefficient is $2.16 \mathrm{E}-05$, and the coefficient tests are not significant. The primary industry like agriculture takes the leading part in the industrial structure, meaning that the majority of population sill live in rural areas, the progress of urbanization has not been finished. The progress is inevitable based on past experiences, and the value of variable will grow with the development of economy.

\section{The Conclusions and Policy Recommendations}

According to the results of regression model there did exist inverted-U-shape curve between GDP per capita and per capita carbon emission. In terms of significance, the influence of energy-consumption structure and energy efficiency are bigger, and the impact of industry structure, global trade and urbanization are smaller. The variables which help to reduce carbon emission include $\mathrm{X}_{5}, \mathrm{X}_{6}$ and $\mathrm{X}_{9}$, showing that the carbon emission will drop as the increase of these variables. The management of ecological problems is a long-term progress, we can set some policies to solve the problems caused by economy growth.

(1) Upgrading the Industrial Structure

Reducing the percentage of secondary industry which is the key cause to carbon emission, and developing low-polluted and low-energy-consumed service industry are the primary task. Some policies need to be set to guide, encourage and help develop low-carbon industry.

(2) Optimizing the Energy Structure

It is not hard to find that coal energy is the main kind energy consumption from the consumption history. Hubei Province should make full use of its location, developing green energy like hydro energy, wind energy and nuclear energy, meanwhile advanced technology is supposed to enhance energy efficiency. This will not only help to ease the shortage of fossil energy, but also decrease the carbon emission largely. 
(3) Increasing the Percentage of FDI

The local infrastructure should be developed to attract foreign investment, because the authority can learn new technology and running methods from the foreign, and also help to transform the trade structure, importing those low-carbon products and advanced technology to release environment pressure.

(4) Popularizing the Low-carbon Lifestyle

The carbon emission increased as the improvement of economic level, but it is far away to solve the problem just by changing the external factors, so it is necessary to enhance the public's self-consciousness of pollution problems and insist on low carbon concept, leading to the popularization of Low-carbon lifestyle.

\section{References}

[1]H. L. Chen, An Analysis on the Effect of Economic Growth in Hubei Province on Carbon Dioxide Emission Kuznets Curve, Hubei Social Science,(2013)52-57. In Chinese

[2] G. M. Grossman, A. B. Kreuger, Economics impact of a North American free trade agreement, NBER Working Paper, 3914, (1991)

[3]D. Zuo, An Analysis on China's Carbon Dioxide Emissions Kuznets Curve Based on Spatial Panel Model, Southeast University of Finance and Economics(2013) In Chinese

[4]G. Q. Xu, Decomposition Model and Empirical Study of Carbon Emissions for China,1995-2004, China Population Resources and Environment,(2006)158-161. In Chinese

[5]C. X. Qi, The Empirical Study on Relationship between Carbon Emission and Economic Growth in China, Northwest Normal University(2012) In Chinese

[6]Y. C. Shen, Does the EKC Exists?--Evidence from Underdeveloped Areas of China, Scientific Decision-Making,(2014)66-84. In Chinese

[7]F. X. Shao, et al. Carbon Emissions and the Environmental Kuznets Curve Factors in Shanxi Province, Journal of Arid Land Resources and Environment,(2012)37-43. In Chinese

[8]G. Y. Xu, An Empirical Study of the Environmental Kuznets Curve for China's Carbon Emission-Based on Province Panel Data, China Industrial Economics,(2010)37-47. In Chinese

[9]B. Q. Lin, An Analysis on China's Carbon Dioxide Emission Kuznets Curve and its prediction, Management World,(2009)27-36. In Chinese

[10]F. C. Liu, An Assessment of China's Energy Consumption Intensity Based on Structure Share and Efficiency Share Methods, Resources Science,(2007)1-6. In Chinese

[11]N. Gu. The Identification of the Environmental Kuznets Curve about the Carbon Emission and the Corresponding Policies of Low-Carbon Economy, Economic Management,(2013)153-163. In Chinese 